\title{
Changing causes of death in Familial Adenomatous Polyposis: 20 years of progress
}

\author{
Lisa LaGuardia*, Margaret O'Malley, Carol Burke, Matthew Kalady, James Church \\ From 13th Annual Meeting of the Collaborative Group of the Americas on Inherited Colorectal Cancer \\ Honolulu, Hawaii, USA. 16-17 October 2009
}

\section{Background}

Patients with FAP are at risk of dying from multiple benign and malignant tumors, from surgical complications, and comorbid diseases. We previously evaluated and published causes of death in FAP patients in 1990. This study analyzes patterns of mortality in the ensuing 2 decades and compares the two time periods to determine if advances in medicine and technology have changed clinical outcomes.

\section{Methods}

Causes of death were extracted from the 1990 study via the manuscript. Causes of death since then were determined from the registry database and confirmed by chart review.

\section{Results}

In 1990 there were 178 FAP families in the registry. Currently, 761 families are enrolled in the registry. The mean age of patients in the registry before 1990 was 36.5 and the mean age since then is 54.5 . There is a significant increase in life expectancy in patients after 1990. 212 patients have died ( 0.28 deaths per family); 110 before 1990 ( 0.62 deaths per family) and 102 since (0.17 deaths per family). Causes of death are listed in Table 1.

"Other" deaths include cancers of the thyroid, stomach, esophagus, pancreas, breast, ovary and lung. There were also 2 suicides and one death from pancreatitis. Overall there have been fewer deaths per family since 1990. Deaths from colorectal and periampullary/ duodenal cancer have declined (even if the "unknown" category is excluded) while those for desmoid remain constant. Perioperative deaths are fewer.

\section{Conclusion}

Although the main causes of death in FAP remain the same, improvements in education and in access to screening and surgical techniques have decreased the overall mortality rates. Continued improvements in all aspects of patient care could further improve patient outcomes in FAP.

\section{Table 1}

\begin{tabular}{lcccc}
\hline Cause of death & Before $\mathbf{1 9 9 0}$ & Age at death & Since 1990 & Age at death \\
\hline Colorectal cancer & $64(58.2 \%)$ & 41.1 & $41(40.2 \%)$ & 49.4 \\
Desmoid disease & $12(10.9 \%)$ & 33.8 & $9(8.8 \%)$ & 34.6 \\
Periampullary cancer & $9(8.2 \%)$ & 49.1 & $4(3.9 \%)$ & 51.7 \\
Brain cancer & $8(7.3 \%)$ & 19.6 & $2(2 \%)$ & 81 \\
Perioperative & $5(4.5 \%)$ & 32.6 & $3(2.9 \%)$ & 0 \\
Accident & $3(2.7 \%)$ & 31.3 & $24(23.5 \%)$ & 59.5 \\
Other & $9(8.2 \%)$ & 38.4 & $19(18.6 \%)$ & 53 \\
Unknown & 0 & 0 & $57(55.9 \%)$ & 57.8 \\
Overall cancer (excluding desmoids) & $85(77.3 \%)$ & &
\end{tabular}

\footnotetext{
* Correspondence: laguarl@ccf.org

Department of Colorectal Surgery, The Sanford R. Weiss, M.D. Center for Hereditary Colorectal Neoplasia, Digestive Disease Institute, Cleveland Clinic, Cleveland, Ohio 44915, USA
} 
doi:10.1186/1897-4287-8-S1-P9

Cite this article as: LaGuardia et al:: Changing causes of death in

Familial Adenomatous Polyposis: 20 years of progress. Hereditary Cancer in Clinical Practice 2010 8(Suppl 1):P9.

Submit your next manuscript to BioMed Central and take full advantage of:

- Convenient online submission

- Thorough peer review

- No space constraints or color figure charges

- Immediate publication on acceptance

- Inclusion in PubMed, CAS, Scopus and Google Scholar

- Research which is freely available for redistribution 